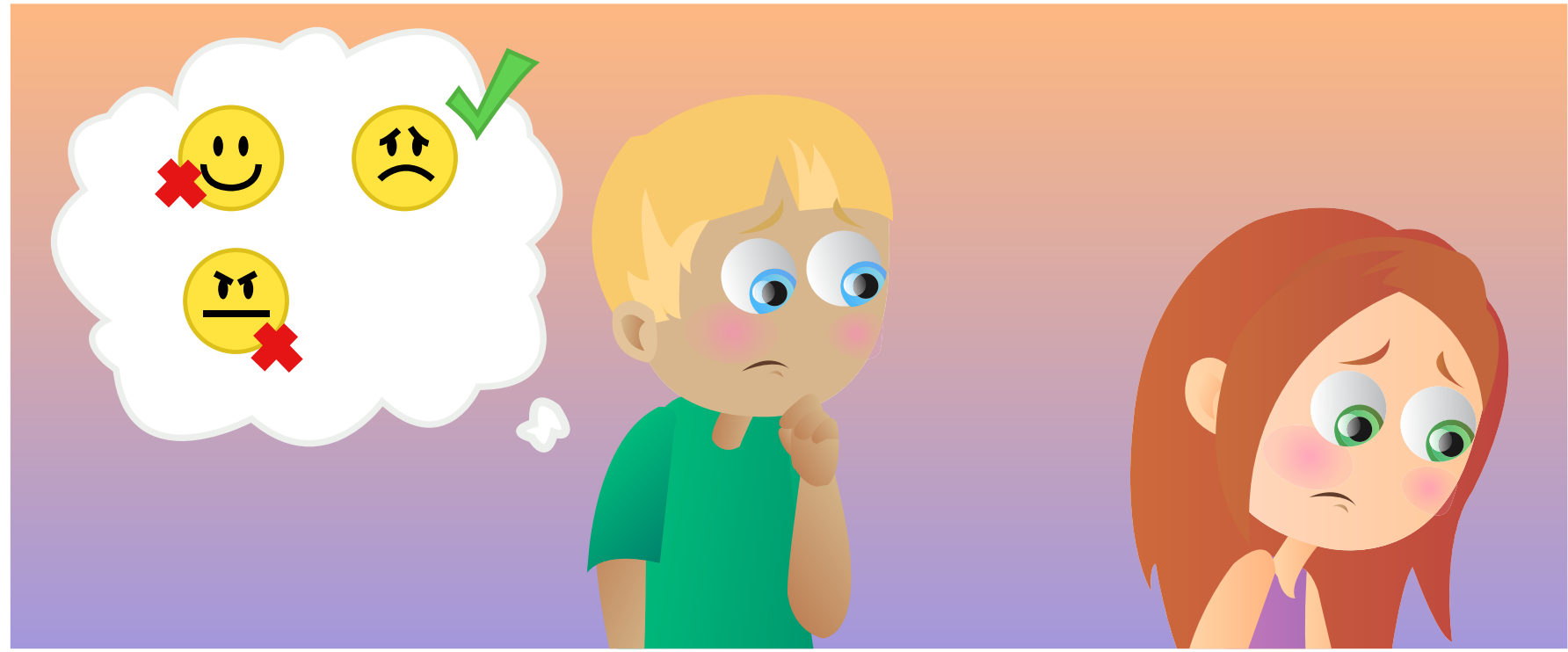

\title{
HOW DO WE UNDERSTAND OTHER PEOPLE?
}

\section{Jennifer Stiso and Anat Perry*}

Helen Wills Neuroscience Institute, University of California Berkeley, Berkeley, CA, USA

\section{REVIEWED BY: \\ $S C H O O L$ \\ OF THE}

MADELEINE

12-13 YEARS OLD
Imagine this: you walk into class and see your friend sitting alone at a table. You notice your friend is looking downward, with a frown on her face. You would probably think from these clues that your friend is sad. But how did you know that? One way that your brain accomplishes this is by simulating or copying in your mind what you see the other person doing. This may help you understand that when you are frowning and looking downward, you are usually sad, so it is probably the case that your friend is sad too. While there are other hypotheses for how our brain understands others, we are going to focus on simulation, and how special cells in the brain - called mirror neurons - may help to make simulation possible. We will first examine neuroimaging experiments, in monkeys and in humans, in which we use technology to get an indication of brain activity. These brain activations help us understand simulation better. Lastly, we will discuss disorders such as autism, in which it may be more difficult to understand others' actions, intentions, and emotions.

We usually do not think about the fact that most of us are really good at understanding others. To illustrate how important this ability is, let us start with an example from the book: "The Curious Incident of the Dog in the 


\section{AUTISM}

A general term for a group of complex disorders of brain development. These disorders are characterized by different levels of difficulty with social interaction, verbal and non-verbal communication, and repetitive behaviors.
Night-Time" by Mark Haddon, which tries to show us how a person with autism sees the world [1]:

My name is Christopher John Francis Boone. I know all the countries of the world and their capital cities and every prime number up to 7,057.

Eight years ago, when I first met Siobhan, she showed me this picture

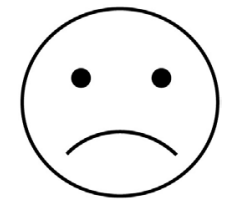

and I knew that it meant "sad," which is what I felt when I found the dead dog.

Then she showed me this picture

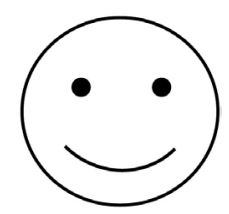

and I knew that it meant "happy," like when I'm reading about the Apollo space missions, or when I am still awake at 3 a.m. or 4 a.m. in the morning and I can walk up and down the street and pretend that I am the only person in the whole world.

Then she drew some other pictures:

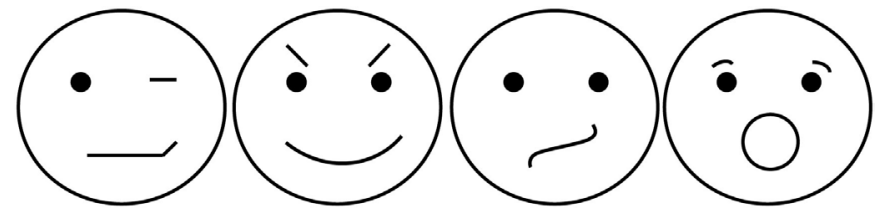

but I was unable to say what these meant.

I got Siobhan to draw lots of these faces and then write down next to them exactly what they meant. I kept the piece of paper in my pocket and took it out when I didn't understand what someone was saying. But it was very difficult to decide which of the diagrams was most like the face they were making because people's faces move very quickly.

When I told Siobhan that I was doing this, she got out a pencil and another piece of paper and said it probably made people feel very

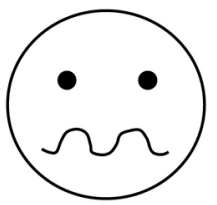




\section{EMPATHY}

The ability to feel what another person is feeling, to "put yourself in that person's shoes."

THEORY THEORY

You learn to understand others by developing and testing theories about their behavior or emotions.

SIMULATION THEORY

You understand others because your brain simulates, or copies, what you see them doing; in other words, your brain is active the same way theirs is.

\section{MIRROR}

\section{NEURON}

A special cell in the brain that responds to two things: seeing a certain action or expression and doing that action or expression yourself.

Now, we are different than the narrator, Christopher. Understanding others' feelings seems easy to us - we are experts at it, and do it almost automatically throughout the day. If you understand that your friend is sad, when you go up to her, you know that you should ask her how she is feeling and try to comfort her. Similarly, you can act appropriately if you interact with new people who seem sad, angry, happy, or anything else. But it is not easy at all! In fact, it is sometimes even impossible for people with certain disorders, such as autism. It may be difficult for people with these disorders to understand the thoughts and feelings of others, to empathize with them (to feel the feelings of others), or for them to even acknowledge that others may have thoughts and feelings that are different from their own.

Philosophers (professional thinkers) and psychologists (people who study human behavior) have been bothered with the question of how we understand others for a long time, long before neuroscience (the study of the brain) was created as a field of study. Philosophers and psychologists came up with many theories, and we will discuss two important competing ones, which are still under debate.

The first theory, often known as "Theory Theory" [2], basically states that people develop their everyday knowledge of the world using the same mental strategies that adults use in science. That is, they make up theories. These theories enable young children to make predictions about new evidence, to interpret evidence, and to explain evidence. So the first time I see my friend looking downward, with a frown on her face, I might initially think she is happy - that would be my first theory about her. However, after a few times when I am proven wrong, I will know this posture probably means she is sad.

The second theory is often called "Simulation Theory" [3]. It essentially says that when we want to understand what someone else is doing, thinking, or feeling, our mind simulates, or recreates, the same actions, as if we were doing them ourselves. From that simulation, the mind figures out what the other person might be feeling. So, if I see my friend looking downward, with a frown on her face, my mind simulates these actions. From that simulation, I understand that when I sit like this, I am generally sad, so I decide that my friend is probably sad too. In some cases, this might cause an "emotional contagion" effect, where the emotions of another person seem to be contagious, or "catching." You smile when seeing another smile or cringe when you see someone in pain (see Figure 1).

While there are many hypotheses for how our brain understands others, we are going to focus on the second theory, simulation theory, and explain how mirror neurons in the brain may be involved in this process. 


\section{FIGURE}

Examples of simulation

The left image, of

someone yawning, often causes others to yawn too (this is known as "the yawning effect"). The middle image might make you cringe, as if feeling the pain of the other, and the right image may make you smile, and even be happy (be careful, these emotions are contagious!).

\section{FUNCTIONAL}

\section{MAGNETIC}

RESONANCE

IMAGING

(FMRI)

A way of looking at brain activity that measures blood flow.

\section{ELECTROENCE-} PHALOGRAPHY

Pronounced: in-lek-trohen-sef-uh-log-ruh-fee; in short: EEG. A way of looking at brain activity from electrodes on someone's scalp that measure the electrical fields created by lots of neurons when they fire.
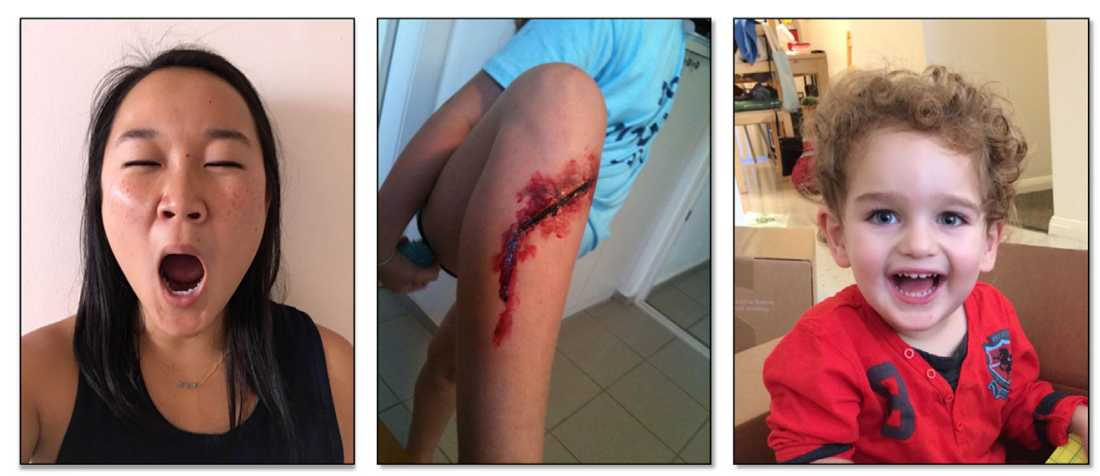

FIGURE 1

\section{WHAT ARE MIRROR NEURONS?}

Mirror neurons are cells in the brain that respond both when you perform a specific action and when you see someone else performing a similar action. Mirror neurons were given this name because they "reflect" the actions of others, just like a mirror. Mirror neurons were first discovered in monkeys by Professor Giacomo Rizzolatti [4]. Professor Rizzolatti and his group used electrodes (measurement devices) in the monkey's brain to record the activity of many individual brain cells. The researchers were interested in the brain's motor system, which controls the movement of the body, and they were looking for cells that would fire when the monkey performed a specific action, like grasping a banana. Surprisingly, some of the brain cells responded both to grasping the banana and to seeing the researcher grasp the banana (Figure 2). Additionally, these cells did not respond to still pictures of food or pictures of the researcher, suggesting that these neurons might be helping the brain represent how the researcher interacted with the banana [4]. The research team thought that the firing of brain cells while watching someone else perform an action could be critical for helping the monkey understand the actions performed by others. While this discovery was very exciting, the researchers knew it was possible that mirror neurons only existed in monkeys and that humans might have a different way of understanding others' actions. More research was needed in humans to figure out if we also have mirror neurons and what role these neurons might play in our ability to understand others.

After the discovery of mirror neurons in the monkey, many human studies were conducted on the mirror neuron system. Some of these studies were done using a technique called functional magnetic resonance imaging (or fMRI), which uses a machine than "scans" the brain and records how much brain activity occurs in each part of the brain at a given time, by detecting changes associated with blood flow. Other studies used a method called electroencephalography (EEG). EEG uses electrodes to measure brain activity but is different from the method used by Dr. Rizzolatti in his monkey research. EEG measures electrical brain activity with electrodes placed on the outside of a person's head, rather than inside the brain. Because the electrodes 
FIGURE 2

An illustration of the monkey mirror neuron experiment. Mirror neurons were active both when the monkey grasped a banana and when it saw the researcher grasp a banana.

\section{ELECTROCORTICO} GRAPHY

Pronounced: in-lek-trohkorti-kog-ruh-fee; in short: ECoG. A way of looking at brain activity from electrodes on someone's brain (underneath the skull). Measures the electric fields created by lots of neurons when they fire. This method can only be used on people who need surgery to treat their epilepsy.

\section{EPILEPSY}

A condition that causes sudden uncontrolled and violent shaking of the body, resulting from repeated muscle contraction and relaxation, called a seizure. Seizures happen when there is unusual electrical activity in the brain.

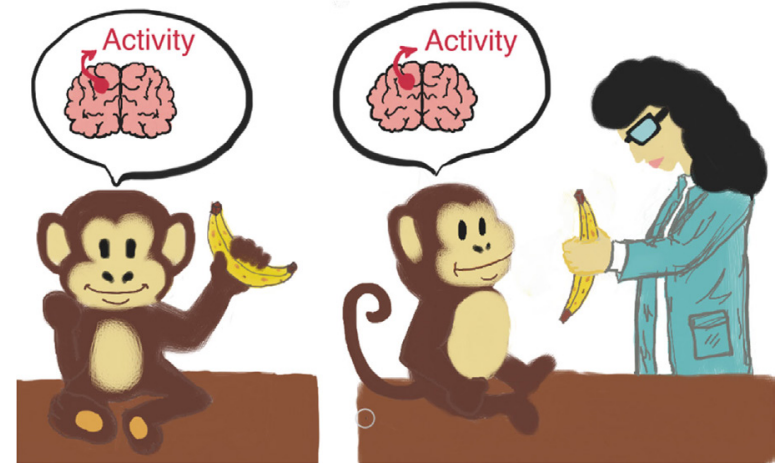

FIGURE 2

are on the outside, EEG can only record the overall activity of many (millions) of neurons at once, rather than one just cell. But, placing the electrodes on the outside of the head is much easier to use for research on humans (see Jennifer's photo!). Using EEG, researchers were able to show brain activity in humans similar to what Professor Rizzolatti saw in the monkey brain. These researchers helped identify the brain regions that respond both to watching someone perform an action and to performing the action yourself. These regions were mostly found in frontal and parietal regions of the brain, as well as in the sensorimotor cortex (see Figure 3 to learn where these brain regions are located) [5]. The brain regions that responded in these experiments have lots of roles and are also active in other tasks, such as planning, talking, the sensation of touch, movement, and making decisions. This shows us how complex the brain is - there is probably not one region for "understanding others," rather there are networks of regions that work together to help you understand different things. EEG and fMRI are very useful, but since they measure the brain activity from the surface of the person's head and not from inside the brain, the results are often not quite as clear as researchers would like.

Lately, we have decided to look at human mirror neurons with a method called electrocorticography (ECoG). ECoG measures brain signals with small electrodes placed underneath a patient's skull. Since this procedure involves risks, it is done only in rare cases, using patients who are already awaiting brain surgery. These patients need the surgery and the electrodes to help treat a disease called epilepsy, which causes seizures in the brain. In some cases, medication does not work to control the epileptic seizures and the only way to treat the seizures is to find and remove the part of the brain that is malfunctioning and causing the seizures. To figure out exactly which part of the brain causes the seizures, neurosurgeons implant these electrodes in the brain for 1 or 2 weeks. During this time, many of the patients volunteer to participate in research, while they have the electrodes implanted directly on the brain (see Figure 3). This enables researchers to learn much more about the brain: ECoG lets us know more precisely which brain area we are measuring while also letting us look at the timing of these events as they take place, in milliseconds (one thousandth of a second). 


\section{FIGURE 3}

A. An illustration of our ECoG experiment. Similar brain regions were active when the patients watched a movie clip of someone grasping an object and when the patients grasped the objects themselves.

B. The top image shows examples of ECoG grids implanted directly on patients' brains.

C. The bottom image on the left shows a model of the brain of an ECoG patient, with the sites that showed mirroring activity in white. The parts of the brain that contain mirror regions are also highlighted in different colors. On the right, we show the average activity of one electrode and see that it shows more activity during both viewing (on the left side of the graph) and grasping (on the right side of the graph).
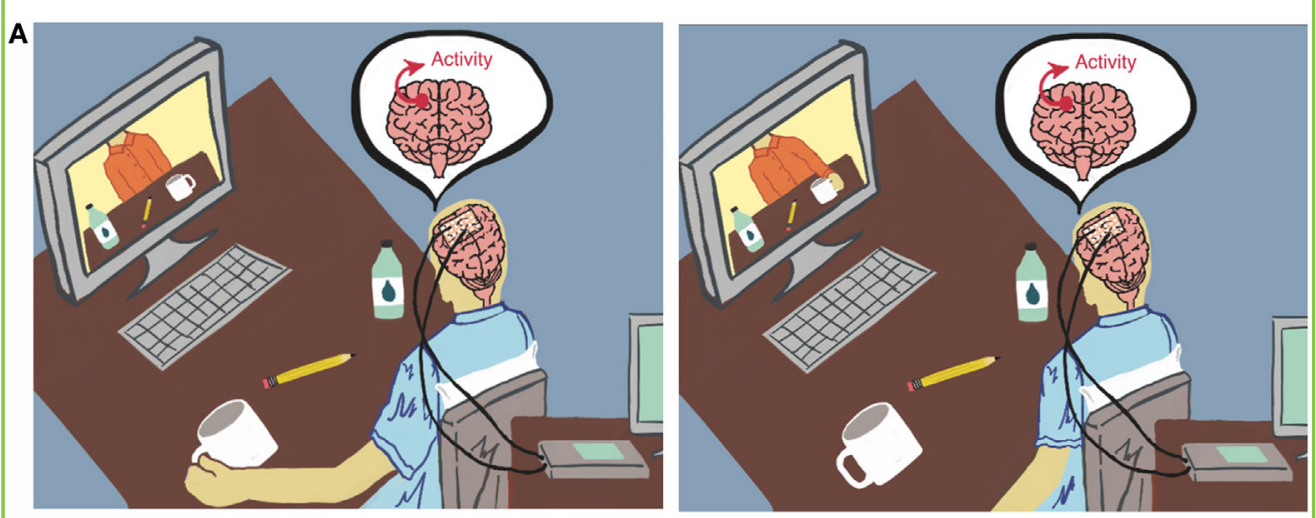

B
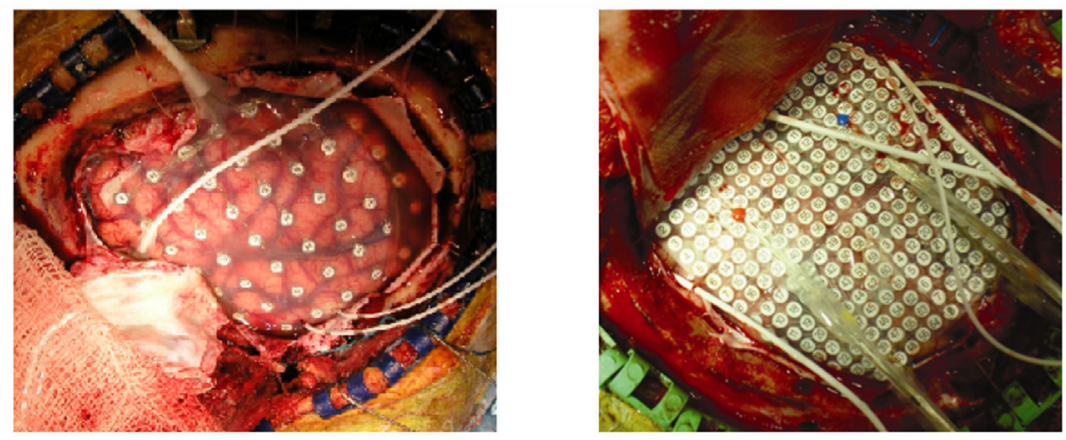

C

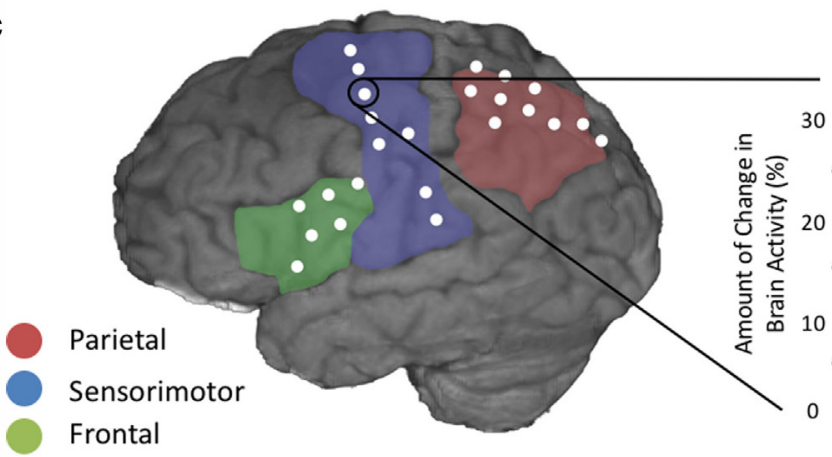

Amount of Brain Activity for One Electrode in Viewing and Grasping

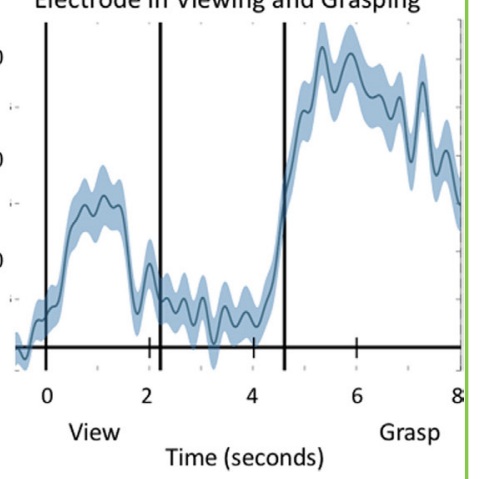

FIGURE 3

In our ECoG experiment, we asked patients to perform a task very similar to the one done with monkeys. Patients saw a video of a hand grasping an object (cup, bottle, or pencil), had to wait and keep the action in their minds, and then were asked to grasp the same object when it was actually in front of them. We saw similar brain activity in mirror neuron regions both when the participants watched the action and when they performed the action themselves (see Figure 3 for an illustration of the design and an example of the results).

The resolution, or clear picture, that the ECoG gave us enabled us to look at more detailed properties of these mirror neuron regions. For example, we found that some of the brain areas were active only when grasping and watching the grasp, while some were also active during the waiting period. The areas 
active during the waiting period might be used for memory purposes, helping us "rehearse" the next movement, and may in fact not be pure mirror neuron sites. In a study using a similar technique, mirror neurons were found for hand actions and for facial expressions in many different brain areas, also outside the classic mirror neuron sites [6]. These results suggest that mirror properties may be found in neurons all around the brain, telling us that they probably have an important role in humans.

\section{CAN WE UNDERSTAND OTHER PEOPLE WHO ARE DIFFERENT FROM US?}

You might find it easy to understand what your friend is going through when she is sad, but it might be more difficult to understand the reactions of people who grew up in a different country than you, have a different religion or set of values, or people with disabilities that you have not experienced. This brings us to an important question: if we use simulation in order to understand others, do we also use it to understand people who are very different from us? Some studies asked exactly this - how do we empathize with someone that is not like us? Let us try to illustrate how such an experiment is conducted. Look at Figure 4 and try to feel what the person in each of the pictures is feeling. Now comes the twist: imagine that the people in these pictures are in fact different from you. These people feel pain when they are touched by a Q-tip but do not feel any pain when being pricked with a needle. Now look at the pictures again and try to feel what these people are feeling. Can you do it?

It turns out that people can understand others who are different from them. And while some brain regions respond automatically to anything that looks painful to us (like being pricked by a needle, perhaps by the process of simulation), other brain regions show activation only when we see the pain of another person, and yet other regions show activation anytime we see anything that seems painful either to ourselves or to the other person, even if the other person experiences pain from different things than I do (for example, for being touched by a Q-tip $[7,8]$ ). Indeed, mirror neurons are probably not the whole story and are part of a broader network of brain regions that help us to understand others [9].

Examples of the pictures shown to participants in experiments for understanding others who are similar to you or different from you. Try to imagine what the people in the figures are feeling. Now try to imagine that these people are different from you: The Q-tip hurts them, but the needle does not. Can you do it?
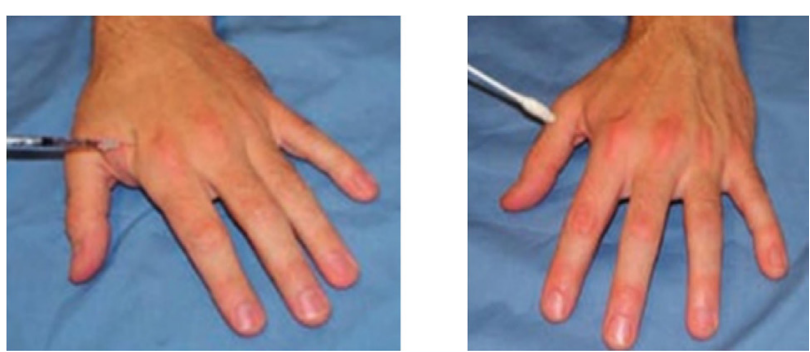

FIGURE 4 


\section{WHAT HAPPENS WHEN WE CANNOT SIMULATE?}

What happens if we cannot properly understand the actions and feelings of others? Some people with disorders like autism have a hard time understanding the actions, intentions, or emotions of others (like Christopher from the story at the beginning of this article). In addition to difficulties interacting with others, these disorders usually also involve repetitive and limited behaviors, difficulties imitating others, and impaired language abilities. People with autism do not look any different than people without it, but they tend to be different that other people in the way they interact socially, just like in the example, we read about at the beginning of this paper. It is important to note that there is a whole range or spectrum of the different symptoms of autism. While it is likely that many different brain processes contribute to the behavioral differences we see in autism, some researchers believe that a failure of the mirror neuron system might be one of the causes [10]. A better understanding of the brain processes that help us to understand others might also contribute to our understanding of these complex social disorders.

\section{CONCLUSION}

The ability to understand others is an important part of our daily lives. Whether it is being able to comfort a friend, or being able to understand the perspective of strangers who may be different from us. One way that our brains might do this is by simulating the actions and feelings of other people with a system of mirror neurons. This way, when we see someone doing a particular action, or looking a particular way, our brains simulate these actions and enable us to understand the other person. This process is usually easy and automatic but may not be as easy for individuals with social disorders such as autism.

\section{ACKNOWLEDGMENTS}

The authors would like to thank Melissa Y. Reyes for her wonderful illustrations for Figures 2 and 3 and the class of young reviewers for their thoughtful suggestions to improve the paper. This work was supported by the EU Marie Curie Global Fellowship (to AP).

\section{REFERENCES}

1. Haddon, M. 2003. The Curious Incident of the Dog in the Night-Time. New York: Doubleday.

2. Gopnik, A., and Wellman, H. M. 1992. Why the child's theory of mind really is a theory. Mind Lang. 7:145-71. doi:10.1111/j.1468-0017.1992.tb00202.x

3. Goldman, A. I. 1992. In defense of the simulation theory. Mind Lang. 7:104-19. doi:10.1111/j.1468-0017.1992.tb00200.x 
4. Gallese, V., Fadiga, L., Fogassi, L., and Rizzolatti, G. 1996. Action recognition in the premotor cortex. Brain 119:593-609. doi:10.1093/brain/119.2.593

5. Rizzolatti, G., and Sinigaglia, C. 2010. The functional role of the parieto-frontal mirror circuit: interpretations and misinterpretations. Nat. Rev. Neurosci. 11:264-74. doi:10.1038/nrn2805

6. Mukamel, R., Ekstrom, A. D., Kaplan, J., lacoboni, M., and Fried, I. 2010. Singleneuron responses in humans during execution and observation of actions. Curr. Biol. 20:750-6. doi:10.1016/j.cub.2010.02.045

7. Lamm, C., Meltzoff, A. N., and Decety, J. 2010. How do we empathize with someone who is not like us? A functional magnetic resonance imaging study. J. Cogn. Neurosci. 22:362-76. doi:10.1162/jocn.2009.21186

8. Perry, A., Bentin, S., Bartal, I. B. A., Lamm, C., and Decety, J. 2010. 'Feeling' the pain of those who are different from us: modulation of EEG in the mu/alpha range. Cogn. Affect. Behav. Neurosci. 10:493-504. doi:10.3758/CABN.10.4.493

9. Zaki, J., and Ochsner, K. 2012. The neuroscience of empathy: progress, pitfalls and promise. Nat. Neurosci. 15:675-80. doi:10.1038/nn.3085

10. Rizzolatti, G., and Fabbri-Destro, M. 2010. Mirror neurons: from discovery to autism. Exp. Brain Res. 200:223-37. doi:10.1007/s00221-009-2002-3

SUBMITTED: 13 April 2016; ACCEPTED: 24 August 2016;

PUBLISHED ONLINE: 14 September 2016.

EDITED BY: Robert T. Knight, University of California, Berkeley, USA

CITATION: Stiso J and Perry A (2016) How Do We Understand Other People? Front. Young Minds 4:18. doi:10.3389/frym.2016.00018

CONFLICT OF INTEREST STATEMENT: The authors declare that the research was conducted in the absence of any commercial or financial relationships that could be construed as a potential conflict of interest.

COPYRIGHT @ 2016 Stiso and Perry. This is an open-access article distributed under the terms of the Creative Commons Attribution License (CC BY). The use, distribution and reproduction in other forums is permitted, provided the original author(s) or licensor are credited and that the original publication in this journal is cited, in accordance with accepted academic practice. No use, distribution or reproduction is permitted which does not comply with these terms.

\section{REVIEWED BY}

\section{SCHOOL OF THE MADELEINE, 12-13 YEARS OLD}

School of the Madeleine is a Catholic elementary school founded in 1937 in the vibrant Dominican tradition of education and service. Part of the Dioceses of Oakland, the mission of the school is to inspire our students to grow in mind, body and spirit. The students who reviewed this article are in the seventh grade. 


\section{AUTHORS}

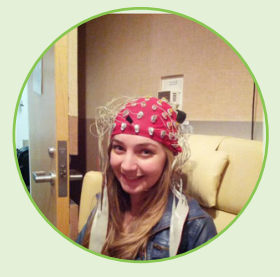

\section{JENNIFER STISO}

I am currently an undergraduate at the University of California Berkeley, but will soon start working towards my $\mathrm{PhD}$ at the University of Pennsylvania. I use brain imaging techniques (like the EEG pictured here) to study human cognition, and I love to teach other people the things I have learned about the brain. When I am not doing research I enjoy playing music (I play the saxophone, marimba, and bassoon), hiking, and playing video games.

\section{ANAT PERRY}

I am currently a postdoc fellow at the University of California Berkeley, and will soon move to Israel, where I plan to start a social cognitive neuroscience lab. I study the way we behave and think in a social world in terms of interactions between the social (social behaviors, cues, contexts, experiences), cognitive (mental processing), and neural (brain) levels of analysis. I do so by applying different research techniques, such as behavioral experiments, neuroimaging (EEG, ECoG, fMRI) and pharmacological (drug) interventions in both healthy and clinical populations. *anat.perry@berkeley.edu, anat.perry@mail.huji.ac.il 